11 This file contains 30 pages, 8 figures and 6 tables.

*Corresponding author:

Hongtao Duan

Email: htduan@niglas.ac.cn; htduan@gmail.com

16 Address: 73 East Beijing Road, Nanjing 210008, China

7 Phone: $+86-25-86882161$

\title{
Satellite estimation of dissolved carbon dioxide concentrations in China's Lake Taihu
}

\author{
Tianci Qi ${ }^{1,3}$, Qitao Xiao ${ }^{1}$, Zhigang Cao ${ }^{1,3}$, Ming Shen ${ }^{1,3}$, Jinge Ma ${ }^{1,3}$, Dong Liu ${ }^{1}$, Hongtao \\ $\operatorname{Duan}^{1,2 *}$ \\ ${ }^{1}$ Key Laboratory of Watershed Geographic Sciences, Nanjing Institute of Geography and \\ Limnology, Chinese Academy of Sciences, Nanjing 210008, China \\ ${ }^{2}$ College of Urban and Environmental Sciences, Northwest University, Xi'an 710127, China \\ ${ }^{3}$ University of Chinese Academy of Sciences, Beijing 100049, P. R. China
}


18 Text S1. Sampling and analysis methods of field data

19 From the TLLER dataset, we calculated the $\mathrm{CCO}_{2}$ based on the field measurements of 20 surface $(\sim 0.5 \mathrm{~m})$ water temperature $\left(\mathrm{T}_{\mathrm{w}}\right), \mathrm{pH}$, and alkalinity (Alk). From our independent

21 cruise and 24-hour continuous observations, we collected surface water samples for the

22 direct measurement of $\mathrm{CCO}_{2}$ using the headspace equilibrium method. The pH-Alk-Tw

23 calculated $\mathrm{CCO}_{2}$ and headspace equilibrium directly measured $c \mathrm{CO}_{2}$ were highly

24 correlated in Lake Taihu. ${ }^{1}$. Other biochemical variables in TLLER dataset considered in

25 this study were chlorophyll-a (Chla), dissolved organic carbon (DOC), total nitrogen (TN),

26 and total phosphorus (TP). Analysis was conducted in laboratory after sampling, and the

27 measurement for these variables can be found in Xiao, et al. ${ }^{1}$. To investigate the

28 relationship between $\mathrm{CCO}_{2}$ and colored dissolved organic matter (CDOM), we also

29 measured absorption coefficients of CDOM at $412 \mathrm{~nm}\left(\mathrm{ag}_{\mathrm{g}}(412)\right)$ for our independent cruise

30 and 24-hour continuous observations based on the method in Xue, et al. ${ }^{2}$ 


\section{Text S2. Satellite data acquisition and processing}

The Moderate Resolution Imaging Spectroradiometer (MODIS)/Aqua Level-1A (L1A)

33

34 data spanning the period between Jul. 2002 and Dec. 2018 with minimal or no cloud cover were chosen and downloaded from the NASA Ocean Color Archive (https://oceandata.sci.gsfc.nasa.gov/). There were a total of 1057 MODIS/Aqua images chosen in this study (Table S1). Then, Level-1B data were generated from the L1A data using SeaWiFS Data Analysis System (SeaDAS) software package (version 7.5) by incorporating the most recent updates within the calibration file (reprocessing version R2018.0; https://oceancolor.gsfc.nasa.gov/cms/reprocessing/r2018/). Then, Rayleighcorrected reflectance $\left(R_{\mathrm{rc}}\right)$ values were derived after correcting for Rayleigh scattering and gaseous absorption effects ${ }^{3}$ in the following MODIS bands: $469 \mathrm{~nm}, 555 \mathrm{~nm}, 645$ $\mathrm{nm}, 859 \mathrm{~nm}, 1240 \mathrm{~nm}$ and $2130 \mathrm{~nm}$. The Second Simulation of the Satellite Signal in the Solar Spectrum correction scheme (6S model) was chosen to derive remote sensing reflectance $(R \mathrm{rs})$ values ${ }^{4}$. The aerosol optical depth (AOD) at $550 \mathrm{~nm}$ (required as an input to the 6SV model) was the $3 \mathrm{~km}$ aerosol product (MYD04_3K) downloaded from NASA's Earth Observing System Data and Information System (EOSDIS, https://earthdata.nasa.gov). The floating algae index (FAl) ${ }^{5}$ was calculated using $R_{\mathrm{rc}}$ data and was then used to mask the algal bloom area (FAl>-0.004). All MODIS data and products with different spatial resolutions were resampled to a resolution of $250 \mathrm{~m}$ to 
ensure that all of the data had the same spatial resolution to support further calculations.

The projection used in this study was UTM 50N.

The MODIS-derived environmental variables for dissolved carbon dioxide concentration $\left(c \mathrm{CO}_{2}\right)$ estimation include the surface chlorophyll-a concentration (Chla), lake surface temperature (LST), diffuse attenuation coefficient of photosynthetically active radiation $\left(K_{\mathrm{d}}(\mathrm{PAR})\right)$, photosynthetically active radiation (PAR) and phytoplankton primary production $\left(P P_{\mathrm{eu}}\right)$. Chla was calculated based on $R_{\mathrm{rc}}$ data using the algorithm developed by Shi, et al. ${ }^{6}\left(R^{2}=0.75\right.$, with a lowest mean absolute relative error of $\left.25.3 \%\right)$. We used the land surface temperature from the MODIS (MYD11A1) product to represent LST, which has been proven to obtain consistent spatial and temporal thermal behavior in Lake Taihu ${ }^{7} . K_{d}(P A R)$ was derived from the diffuse attenuation coefficient at $490 \mathrm{~nm}\left(K_{d}(490)\right)$, which was calculated based on $R_{\mathrm{rs}}$ data using the algorithm developed by Huang, et al. ${ }^{8}\left(R^{2}=0.69\right.$, with an absolute relative error of $\left.19.29 \pm 14.34 \%\right)$. PAR products were from the NASA Ocean Color Archive and were derived using the method proposed by Frouin, et al. ${ }^{9}$. $P P_{\text {eu }}$ was estimated using a vertically generalized production model (VGPM) with MODIS data, which has been proven suitable for Lake Taihu by Deng, et al. ${ }^{10}\left(R^{2}=0.75\right.$, with an absolute relative error of $40.50 \%$ ).

To maximize the number of possible matching pairs between the in situ and satellite observations without compromising quality, the acceptable time interval was relaxed to 5 h. A spatial homogeneity test was then applied to the satellite data ${ }^{11}$; the test required 
70 half of the pixels in the $3 \times 3$ pixel window centered around the in situ stations to have valid 71 data, and the variance limit for these valid pixels was $<10 \%$. Eighty matchups were 72 obtained from the Taihu Laboratory for Lake Ecosystem Research (TLLER) datasets, and 736 matchups were obtained from the independent cruise according to the strict criteria. We 74 divided the TLLER matchups by picking one from every three matchups after reordering 75 by ascending $\mathrm{CCO}_{2}$. Finally, we got 54 matchups representing the development dataset and 26 representing the validation dataset. The 6 matchups of independent cruises were

77 used as independent validation datasets. To ensure spatial data consistency, Rrs or Rrc 78 matchups were derived by averaging a $3 \times 3$-pixel window centered around the in-situ 79 stations. Histograms of the input variables of the 86 pixel-sample matchups were shown 80 in Figure S1. 


\section{$81 \quad$ Text S3. Model training}

82 First, a stepwise multivariate linear regression (MLR) was conducted to determine the 83 independent variables (Chla, LST, $K_{d}(\mathrm{PAR})$, PAR and $P P_{\text {eu }}$ ) that should be used to 84 estimate $\mathrm{CCO}_{2}$. A stepwise routine of both forward and backward was applied for model 85 training according to the Akaike information criterion (AIC). The significance of each input 86 variable was defined by the change in AIC. If AIC increase with variable add, or decrease

87 with variable removal, the variable would be defined as not significant for the regression 88 model. In the stepwise routine, $P P_{\text {eu }}$ did not pass the stepwise regression test, and Chla,

91 orthogonal function (EOF).

92 Then, the stepwise routine was conducted, and all four modes were retained. This result 93 was recorded as the EOF model. Since $P P_{\text {eu }}$ was significantly correlated with EOF 94 transformed mode $1\left(R^{2}=0.74, p<0.01\right), P P_{\text {eu }}$ was used to replace Mode 1 to enhance 95 the theoretical implications of the model. $P P_{\text {eu }}$ and the other modes passed the test of the 96 stepwise routine, and the results were recorded as the PPEOF model. Previous studies

97 have shown that the quadratic polynomial equation can describe the relationship between $98 \mathrm{CCO}_{2}$ and environmental variables in complex water bodies such as coastal waters ${ }^{12}$, so 99 a quadratic polynomial regression (QPR) was conducted using Chla, LST, $K_{d}(P A R)$, and 100 PAR as independent variables to obtain the QPR model. A stepwise regression was also 
101 conducted to simplify the terms of the equation, and the result was recorded as the 102 stepwise QPR (SQPR) model. As the last term (Chla $\times$ PAR) in SQPR model was not 103 significant, with a $p$ value of 0.17 , we removed this term and proposed another model 104 (mSQPR) with all terms being significant. In summary, six empirical models (MLR, EOF, 105 PPEOF, QPR, SQPR and mSQPR) were established for model validation.

106 The structure of the mSQPR model differed from that used in the study of Valerio, et al.

10713 in the Lower Amazon River, who estimates partial pressure of dissolved $\mathrm{CO}_{2}$ from a 108 quadratic polynomial equation of CDOM absorption and water temperature. It was mostly 109 because Lake Taihu is a net autotrophic ecosystem ${ }^{14}$, the temporal variation of dissolved $110 \mathrm{CO}_{2}$ in Lake Taihu was influenced by Chla, water temperature, $K_{\mathrm{d}}(\mathrm{PAR})$ and PAR, the 111 input variables in equation (1). The quadratic terms of Chla and $K_{d}(P A R)$ both indicated 112 dynamics of balance between photosynthesis and organic matter breakdown, because 113 Chla and $K_{d}(\mathrm{PAR})$ not only influenced primary production, but also induced the 114 degradation due to algal-derived organic matter accumulation ${ }^{15}$ and photochemical 115 mineralization ${ }^{16}$. The negative term of LST suggested high water temperature lower the 116 dissolved $\mathrm{CO}_{2}$ (Table S2). 


\section{Text S4. Metric definitions}

118 In this study, standard statistical metrics, including the coefficient of determination $\left(R^{2}\right)$, 119 root mean square error $(R M S E)$, mean bias $(M B)$, mean ratio $(M R)$, unbiased percent 120 difference $(U P D)$, and mean relative difference $(M R D){ }^{17}$, were used to quantify the 121 accuracy of the estimated $\mathrm{CCO}_{2}$ of the different models. These metrics are defined as 122 follows:

$$
\begin{aligned}
& \text { RMSE }=\sqrt{\frac{1}{N} \sum_{i=1}^{N}\left(y_{i}-x_{i}\right)^{2}} \\
& M B=\frac{1}{N} \sum_{i=1}^{N}\left(y_{i}-x_{i}\right)
\end{aligned}
$$

$$
M R=\frac{1}{N} \sum_{i=1}^{N}\left(y_{i} / x_{i}\right)
$$

$U P D(\%)=\frac{1}{N} \sum_{i=1}^{N} \frac{\left|y_{i}-x_{i}\right|}{y_{i}+x_{i}} \times 200 \%$

$$
\operatorname{MRD}(\%)=\frac{1}{N} \sum_{i=1}^{N} \frac{y_{i}-x_{i}}{x_{i}} \times 100 \%
$$

128 where $N$ is the number of data pairs, the subscript $i$ denotes an individual data point, and $129 \mathrm{x}$ and $\mathrm{y}$ represent measured and estimated $\mathrm{CCO}_{2}$, respectively. All analyses were conducted using MATLAB 2016a. 
134 Under the influence of the given uncertainty (Table S5), the model was insensitive to 135 changes in LST and $K_{d}(P A R)$. UPDs of the newly estimated value and the original 136 estimated value were all less than $7 \%$. The model was most sensitive to changes in Chla $137 \quad\left(R M S E=7.76 \mu \mathrm{mol} \mathrm{L}^{-1}\right.$ and $\left.U P D=19.08 \%\right)$ and second-most sensitive to changes in 138 PAR $(R M S E=4.08 \mu \mathrm{mol} \mathrm{L}-1$ and $U P D=10.18 \%)$. Similar to the sensitivity to a single 139 variable, the uncertainty of the pairwise combinations containing Chla was relatively 140 larger. Among the pairwise combinations, the combination of Chla and PAR had the 141 largest uncertainty (UPD $=22.22 \%$, Table S5). Among the three-variable combinations, 142 the combinations without Chla had the smallest uncertainty (UPD=15.40\%). The 143 uncertainty was largest for the combination of Chla, $K_{d}(P A R)$, and PAR (UPD=24.38\%).

144 The UPD for the combination of all variables was only approximately $2 \%$ higher than the $145 U P D$ of the three-variable combination of Chla, $K_{d}(P A R)$ and PAR. In general, the 146 combined effect of the uncertainties of all input variables was relatively small $(R M S E=$ $14710.24 \mu \mathrm{mol} \mathrm{L}-1$ and $U P D=26.14 \%$ ), accounting for only approximately $9 \%$ of the range 148 of the variation in $\mathrm{cCO}_{2}$ data that were used to construct the model $\left(7.73-119.34 \mu \mathrm{mol} \mathrm{L}^{-}\right.$ $149 \quad 1)$. 
150 Text $\mathrm{S6} \mathrm{CO}_{2}$ gas transfer coefficient calculation

151 We calculated the $\mathrm{CO}_{2}$ gas transfer coefficient $\mathrm{k}$ based on the empirical model proposed

152 by Cole and Caraco ${ }^{18}$. In this model, the gas transfer coefficient $k$ is wind-dependent and

153 is normalized to a Schmidt number 600 of a gas at temperature of $20^{\circ} \mathrm{C}$,

$$
k=k_{600} \times\left(S_{c} / 600\right)^{-n}
$$

155 where $S_{c}$ is the Schmidt number for $\mathrm{CO}_{2}$ at in-situ water temperature $\left(\mathrm{t},{ }^{\circ} \mathrm{C}\right)$ :

$$
S_{c}=1911.1-118.11 t+3.4527 t^{2}-0.04132 t^{3}
$$

157 For the exponent $n$, we used the value $2 / 3$ at low wind speed $\left(U_{10}<3.7 \mathrm{~m} \mathrm{~s}^{-1}\right)$ and the 158 value of $1 / 2$ at high wind speed $\left(U_{10}>3.7 \mathrm{~m} \mathrm{~s}^{-1}\right)$. An empirical relationship was used to 159 determine $k_{600}\left(\mathrm{~cm} \mathrm{~h}^{-1}\right.$; Cole and Caraco, 1998):

$$
k 600=2.07+0.215 U_{10}^{1.7}
$$

161 where $U_{10}$ is the wind speed $\left(\mathrm{m} \mathrm{s}^{-1}\right)$ at a $10-\mathrm{m}$ height.

162 Water temperature was from MODIS-derived lake surface temperature. Wind speed 163 was from daily wind speed at Dongshan meteorological stations of Lake Taihu¹. 

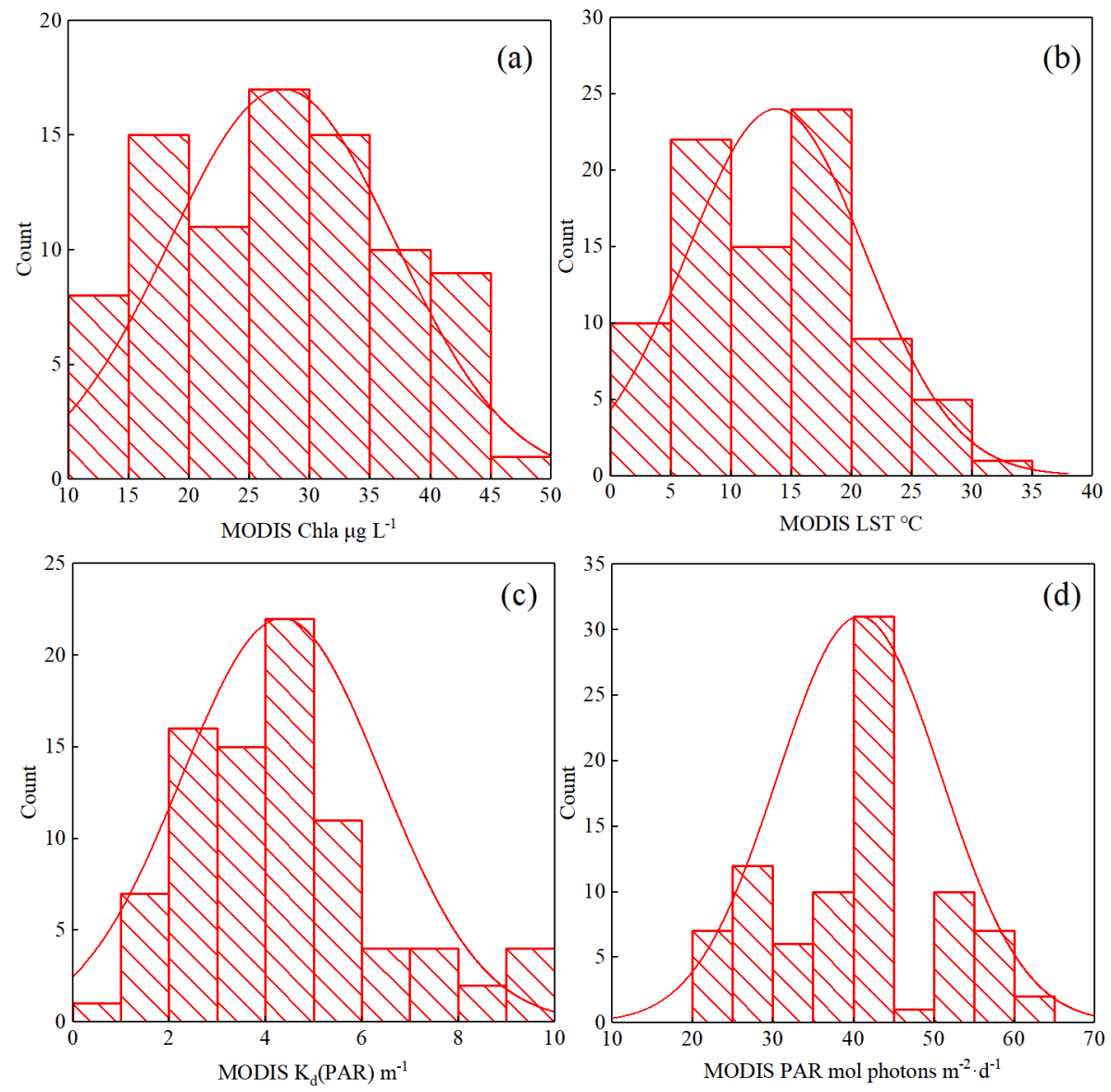

165 Figure S1. Histograms of model input variables of pixel-sample matchups: MODISderived chlorophyll-a (Chla, a), lake surface temperature (LST, b), diffuse attenuation coefficient of photosynthetically active radiation $\left(K_{d}(P A R), c\right)$ and photosynthetically active radiation (PAR, $\mathrm{d}) . \mathrm{N}=86$. 

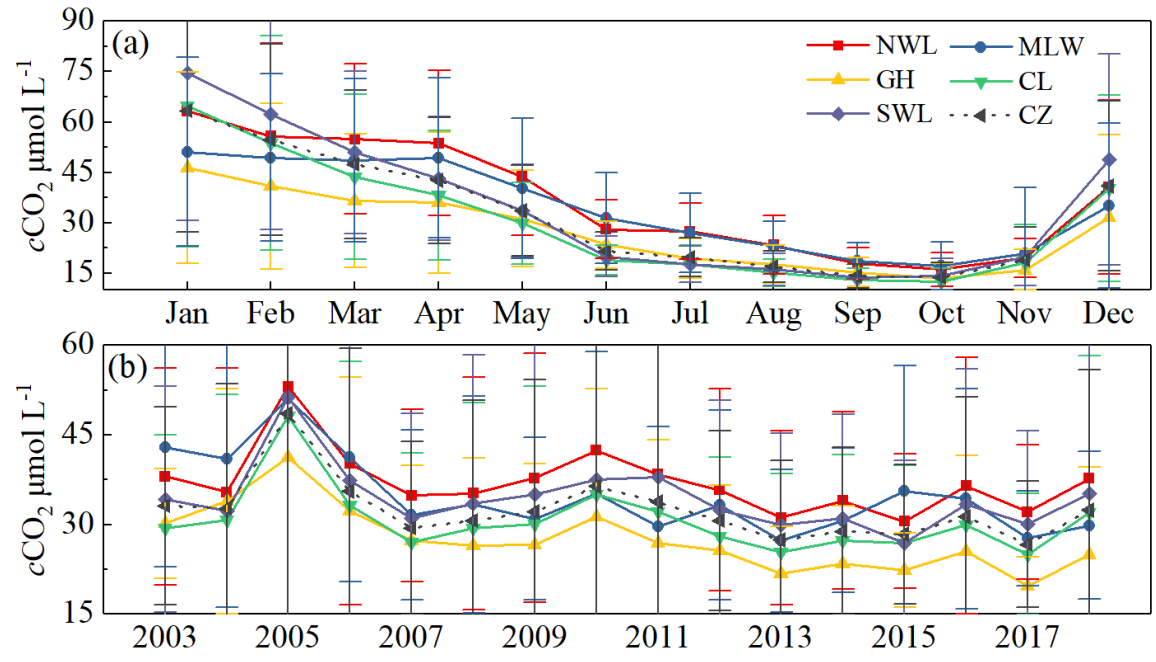

170 Figure S2. Time series of monthly (a) and annual (b) mean carbon dioxide concentration

$171\left(\mathrm{CCO}_{2}\right)$ derived from Aqua-MODIS data from 2003 to 2018 for the Northwest Lake (NWL),

172 Meiliang Bay (MLW), Gonghu Bay (GH), Central Lake (CL), Southwest Lake (SWL) and

173 the whole cyanobacteria-dominated zone $(\mathrm{CZ})$. The error bars indicated standard 174 deviations. 


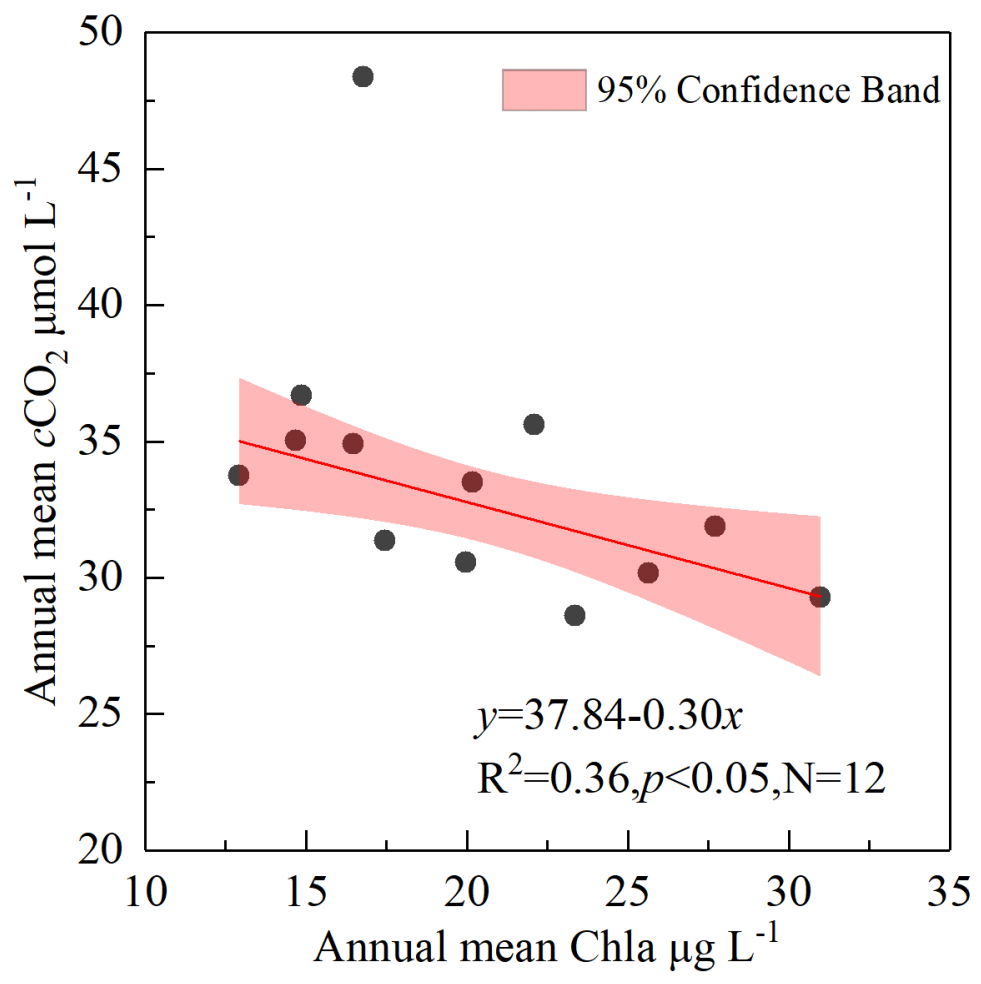

177 Figure S3. Relationship between annual mean MODIS-estimated carbon dioxide 178 concentration $\left(c C_{2}\right)$ and annual mean measured chlorophyll-a (Chla) from 2003 to 2015.

179 The equation was the result of linear regression for annual mean $\mathrm{CCO}_{2}$ and Chla from 1802003 to 2015 except 2005 . The red shading was the $95 \%$ confidence band of linear fit. 181 The $p$ value indicated the significance of slope. 

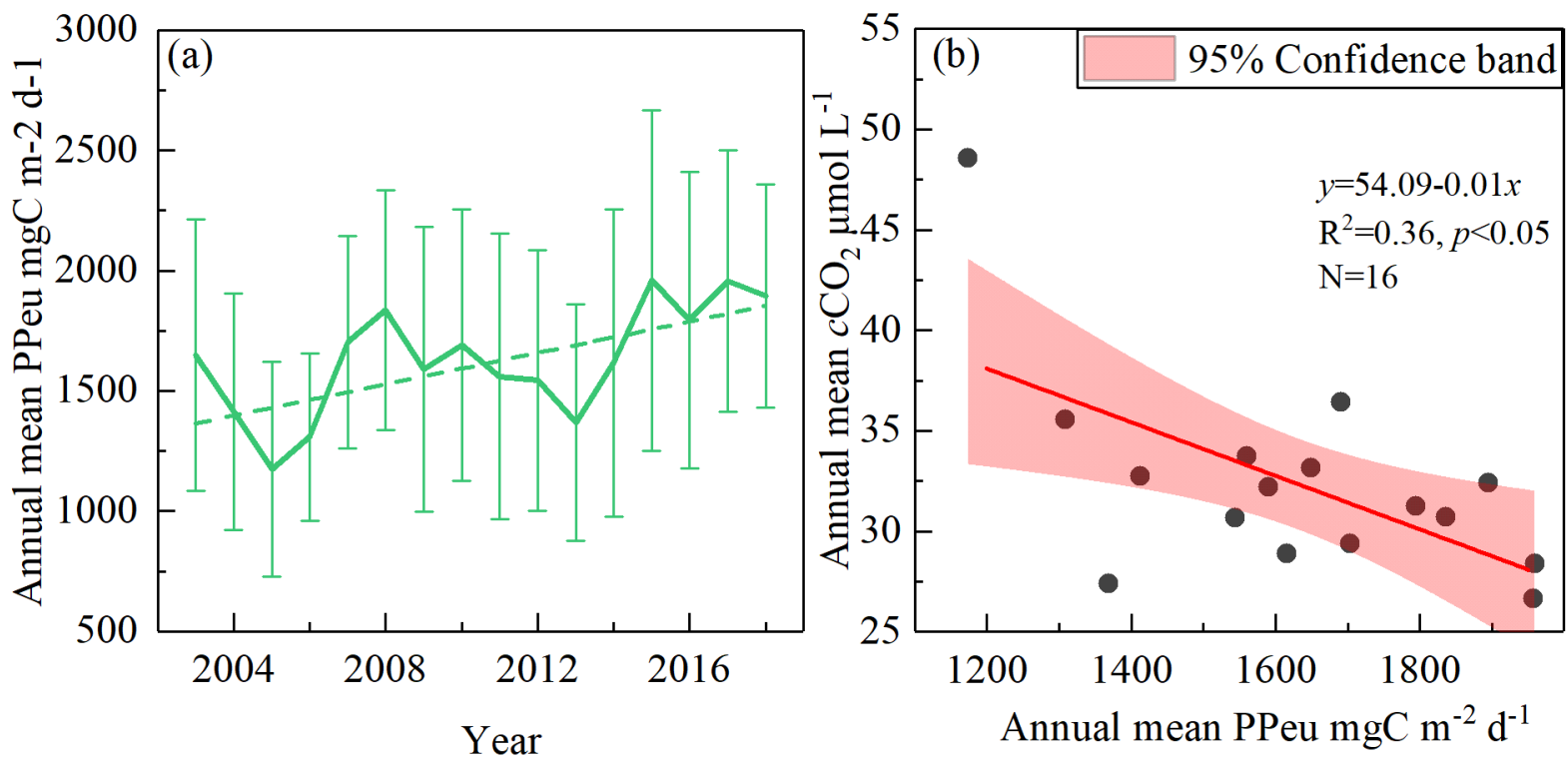

184 Figure S4. Time series of annual mean MODIS-estimated phytoplankton primary 185 production $\left(P P_{\text {eu}}\right)(\mathrm{a})$ and relationship between annual mean MODIS-estimated carbon 186 dioxide concentration $\left.\left(C^{C O}\right)_{2}\right)$ and $P P_{\text {eu }}(\mathrm{b})$ from 2003 to 2018. The green error bar was 187 standard deviations of monthly mean $P P_{\text {eu }}$ in each year. The green dashed line was the 188 linear fitted line of $P P_{\text {eu. }}$. The equation was the result of linear regression for annual mean $189 \mathrm{CCO}_{2}$ and $P P_{\text {eu }}$ from 2003 to 2018 . The red shading was the $95 \%$ confidence band of 190 linear fit. The $p$ value indicated the significance of slope. The error bars indicated standard 191 deviations. 


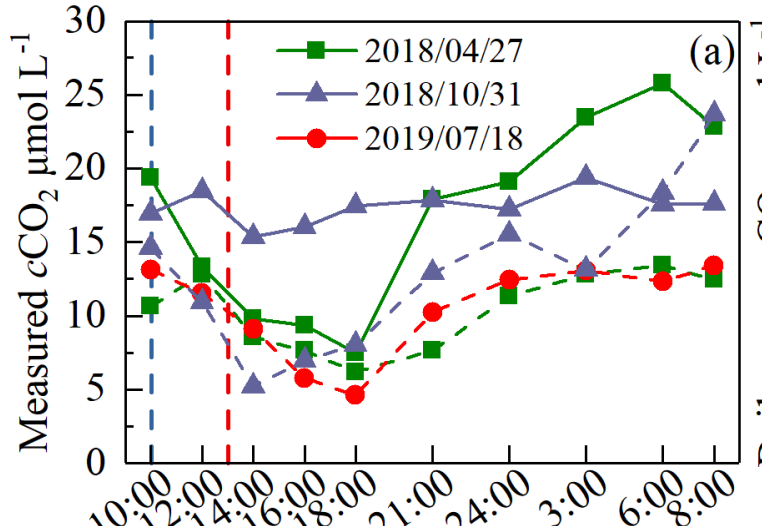

Local time

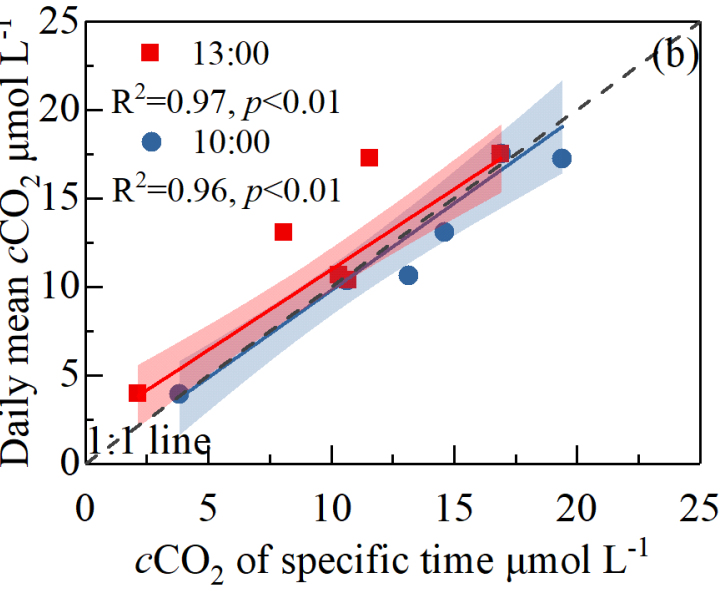

194 Figure S5. Diurnal cycle of carbon dioxide concentration $\left(c \mathrm{CO}_{2}\right)$ measured by headspace method (a) and linear correlations between daily mean $\mathrm{CCO}_{2}$ and $\mathrm{cCO}_{2}$ at regular satellite sensing times for Lake Taihu (b). The straight lines and dashed lines in (a) represent the

197 sites in Central Lake and Meiliang Bay, respectively. Locations of sites were shown in Figure 1. Vertical dashed lines at 10:00 and 13:00 in (a) represent the common satellite sensing times. Blue and red shadings in (b) were the $95 \%$ confidence bands of linear fit 


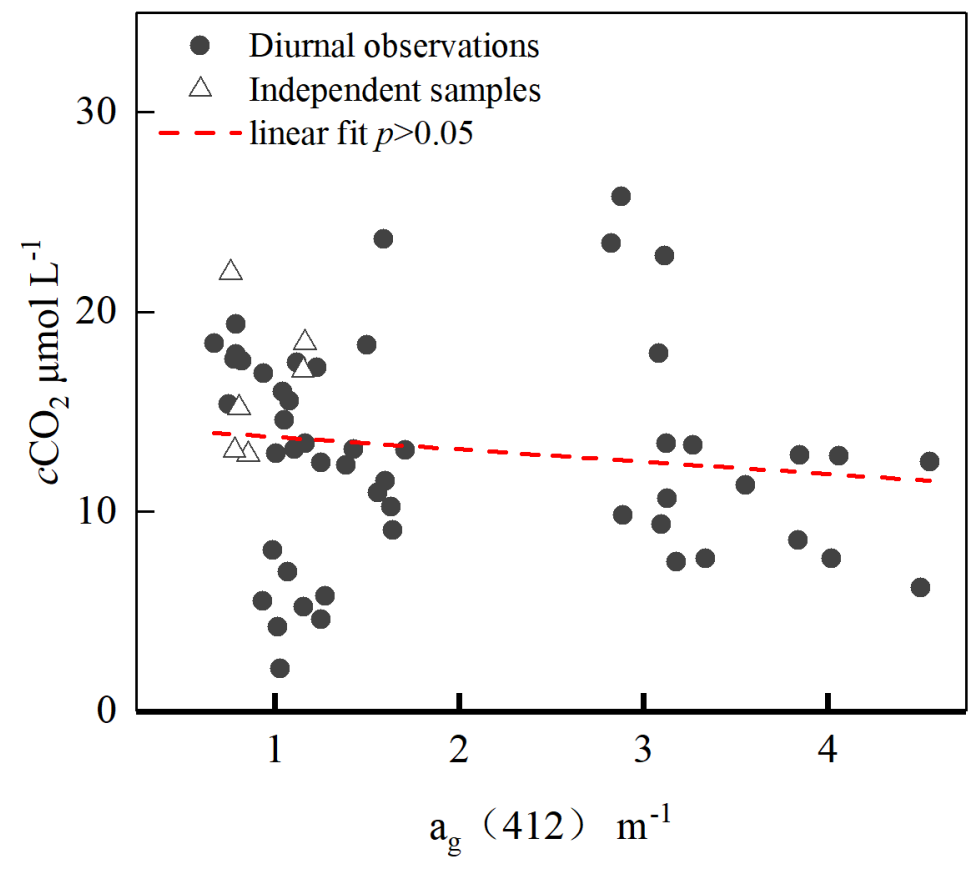

201

202 Figure S6. Scatter plot between CDOM absorption at $412 \mathrm{~nm}\left(\mathrm{ag}_{\mathrm{g}}(412)\right)$ and carbon 203 dioxide concentration $\left(\mathrm{CCO}_{2}\right)$ of samples from diurnal observations (black circles) in 24204 hour cycles on April 27, 2018, October 31, 2018, and July 18, 2019, and the independent 205 cruise (hollow triangles) on November 1, 2019. Locations of sites were shown in Figure 206 1. Number of samples was 57. 


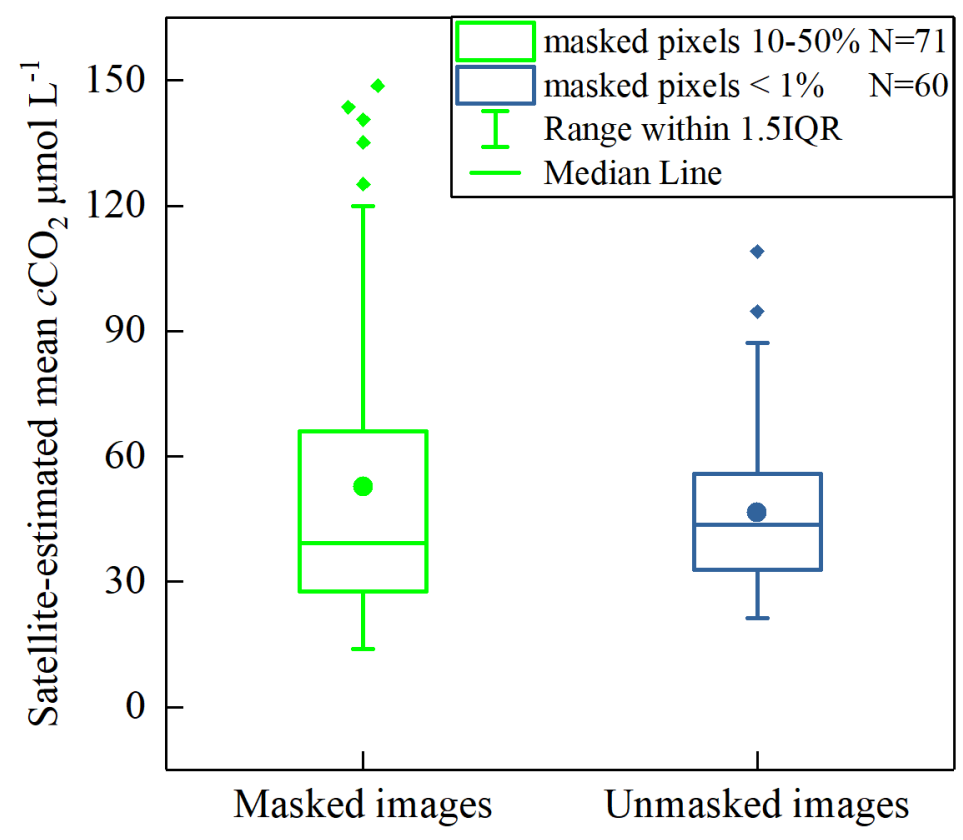

207

208 Figure S7. Box plot of satellite-estimated cyanobacteria-dominated zone mean carbon

209 dioxide concentration $\left(\mathrm{CCO}_{2}\right)$ for winter MODIS images with pixels masked (10-50\%) and 210 images with no pixels masked $(<1 \%)$ through 2003-2018. 

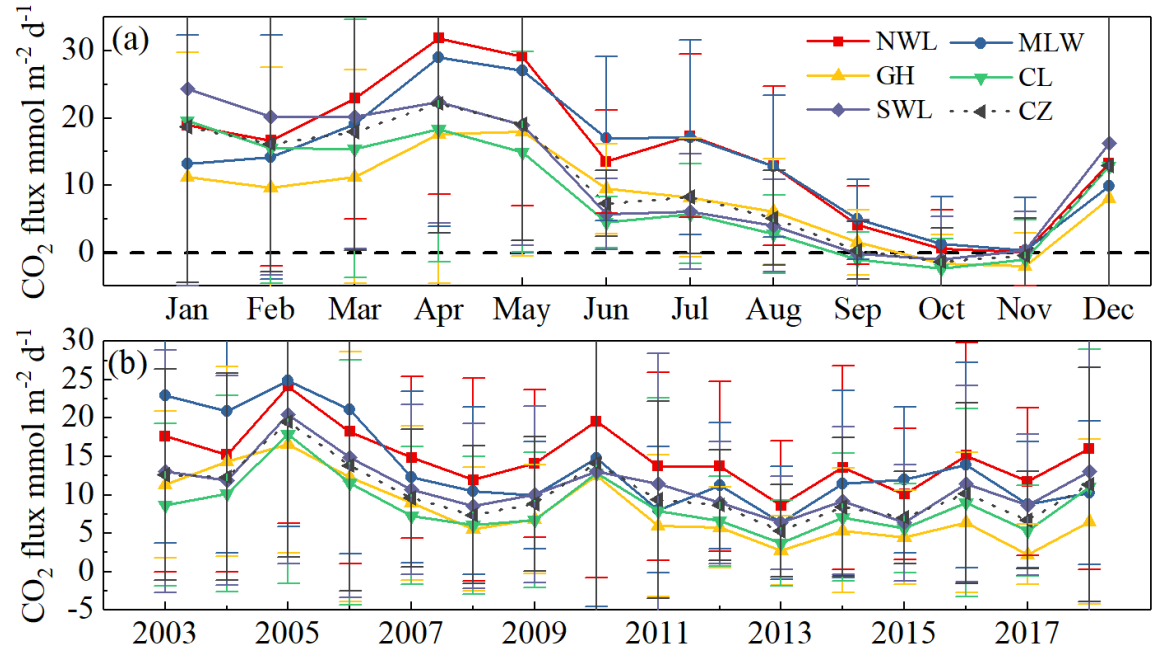

212 Figure S8. Time series of monthly (a) and annual (b) mean carbon dioxide concentration

$213\left(c \mathrm{CO}_{2}\right)$ flux across air-water interface derived from MODIS-Aqua data from 2003 to 2018

214 for the Northwest Lake (NWL), Meiliang Bay (MLW), Gonghu Bay (GH), Central Lake 215 (CL), Southwest Lake (SWL) and the whole cyanobacteria-dominated zone (CZ). Error

216 bars were the standard deviations of all months and years. The error bars indicated 217 standard deviations. 
218 Table S1. Temporal distribution of MODIS-Aqua images used in this study.

\begin{tabular}{llllllllllllll}
\hline year & Jan & Feb & Mar & Apr & May & Jun & Jul & Aug & Sep & Oct & Nov & Dec & total \\
\hline 2002 & $\backslash$ & $\backslash$ & $\backslash$ & $\backslash$ & $\backslash$ & $\backslash$ & 2 & 1 & 5 & 4 & 2 & $\backslash$ & 14 \\
2003 & 3 & 4 & 4 & 5 & 3 & 2 & 2 & 6 & 9 & 7 & 3 & 3 & 51 \\
2004 & 3 & 3 & 5 & 10 & 2 & 3 & 6 & 8 & 6 & 7 & 3 & 1 & 57 \\
2005 & 1 & 2 & 6 & 6 & 7 & 3 & 1 & 4 & 7 & 8 & 4 & 10 & 59 \\
2006 & 3 & 3 & 4 & 5 & 6 & 5 & 5 & 9 & 4 & 2 & 3 & 5 & 54 \\
2007 & 6 & 7 & 6 & 10 & 9 & 1 & 3 & 11 & 4 & 5 & 5 & 2 & 69 \\
2008 & 2 & 8 & 6 & 5 & 5 & $\backslash$ & 4 & 3 & 3 & 2 & 5 & 11 & 54 \\
2009 & 8 & 2 & 5 & 8 & 5 & 4 & 1 & 3 & 6 & 11 & 3 & 4 & 60 \\
2010 & 5 & 1 & 7 & 5 & 5 & 3 & 1 & 18 & 6 & 4 & 5 & 12 & 72 \\
2011 & 7 & 6 & 6 & 13 & 5 & 3 & 4 & 3 & 10 & 7 & 3 & 8 & 75 \\
2012 & 4 & 4 & 10 & 6 & 8 & 5 & 11 & 7 & 8 & 10 & 4 & 6 & 83 \\
2013 & 6 & 2 & 5 & 8 & 7 & $\backslash$ & 7 & 5 & 7 & 12 & 10 & 5 & 74 \\
2014 & 7 & 1 & 10 & 5 & 6 & 3 & 5 & 3 & 3 & 10 & 4 & 13 & 70 \\
2015 & 6 & 4 & 2 & 6 & 5 & 3 & 7 & 6 & 6 & 10 & 2 & 5 & 62 \\
2016 & 5 & 11 & 5 & 3 & 3 & 3 & 4 & 6 & 5 & 1 & 7 & 9 & 62 \\
2017 & 7 & 7 & 6 & 8 & 7 & 1 & 4 & 7 & 4 & 8 & 6 & 8 & 73 \\
2018 & 3 & 9 & 10 & 7 & 5 & 1 & 9 & 9 & 3 & 4 & 4 & 4 & 68 \\
total & 76 & 74 & 97 & 110 & 88 & 40 & 76 & 109 & 96 & 112 & 73 & 106 & 1057 \\
\hline & & & & & & & & & & & & &
\end{tabular}


222 Table S2. Pearson correlation coefficients between variables for all 86 pixel-sample 223 matchups.

\begin{tabular}{|c|c|c|c|c|c|c|}
\hline & Chla & $\ln (\mathrm{LST})$ & $\ln \left(K_{d}(P A R)\right)$ & PAR & $\ln \left(P P_{\text {eu }}\right)$ & $\ln \left(\mathrm{cCO}_{2}\right)$ \\
\hline Chla & 1 & & & & & \\
\hline $\ln (\mathrm{LST})$ & -0.2 & 1 & & & & \\
\hline $\ln \left(K_{d}(P A R)\right)$ & $-0.39^{* *}$ & $-0.46^{\star *}$ & 1 & & & \\
\hline PAR & 0.06 & $0.70^{\star *}$ & $-0.36^{\star *}$ & 1 & & \\
\hline $\ln \left(P P_{\mathrm{eu}}\right)$ & $0.54^{* *}$ & $0.62^{* *}$ & $-0.87^{* *}$ & $0.54^{* *}$ & 1 & \\
\hline $\ln \left(\mathrm{cCO}_{2}\right)$ & $0.25^{\star}$ & $-0.75^{\star \star}$ & $0.54^{* \star}$ & $-0.31^{\star *}$ & $-0.52^{* *}$ & 1 \\
\hline
\end{tabular}

224 Chla: chlorophyll-a; LST: lake surface temperature; $K_{d}(\mathrm{PAR})$ : diffuse attenuation 225 coefficient of photosynthetically active radiation; PAR: photosynthetically active radiation; $226 P P_{\text {eu: }}$ phytoplankton primary production; $c \mathrm{CO}_{2}$ : carbon dioxide concentration. ${ }^{*} p<0.05$; $227 \quad{ }^{* *} p<0.01$ 
Table S3. Comparison of different models for different dataset.

\begin{tabular}{|c|c|c|c|c|c|c|}
\hline Dataset & Models & $\begin{array}{l}\text { RMSE } \\
\text { umol L-1 }\end{array}$ & $\begin{array}{l}\text { UPD } \\
\%\end{array}$ & $\begin{array}{l}\text { MRD } \\
\%\end{array}$ & $\begin{array}{l}M B \\
\mu \mathrm{mol} \mathrm{L}^{-1}\end{array}$ & $M R$ \\
\hline \multirow{6}{*}{$\begin{array}{l}\text { Training } \\
\mathrm{N}=54\end{array}$} & MLR & 12.32 & 24.37 & 5.40 & -1.89 & 1.05 \\
\hline & EOF & 12.39 & 24.37 & 5.41 & -2.04 & 1.05 \\
\hline & PPEOF & 11.70 & 25.48 & 5.96 & -2.00 & 1.06 \\
\hline & QPR & 11.97 & 20.91 & 3.51 & -1.03 & 1.04 \\
\hline & SQPR & 12.34 & 21.83 & 3.74 & -1.18 & 1.04 \\
\hline & mSQPR & 11.81 & 22.46 & 3.92 & -1.20 & 1.04 \\
\hline \multirow{6}{*}{$\begin{array}{l}\text { Validation } \\
\mathrm{N}=26\end{array}$} & MLR & 13.34 & 26.14 & 8.89 & -0.52 & 1.09 \\
\hline & EOF & 13.28 & 26.05 & 8.86 & -0.67 & 1.09 \\
\hline & PPEOF & 13.08 & 27.66 & 9.53 & -1.18 & 1.10 \\
\hline & QPR & 14.57 & 25.99 & 4.66 & -0.84 & 1.05 \\
\hline & SQPR & 15.12 & 27.09 & 6.34 & -0.34 & 1.06 \\
\hline & mSQPR & 14.71 & 27.30 & 6.97 & 0.01 & 1.07 \\
\hline \multirow{6}{*}{$\begin{array}{l}\text { Independent } \\
\text { validation } \\
\mathrm{N}=6\end{array}$} & MLR & 8.16 & 49.24 & -36.06 & -6.69 & 0.64 \\
\hline & EOF & 8.38 & 50.91 & -37.49 & -6.92 & 0.63 \\
\hline & PPEOF & 8.37 & 50.84 & -38.66 & -7.04 & 0.61 \\
\hline & QPR & 4.15 & 20.35 & -17.08 & -3.19 & 0.83 \\
\hline & SQPR & 6.32 & 40.08 & -32.74 & -5.69 & 0.67 \\
\hline & mSQPR & 7.14 & 47.16 & -37.46 & -6.48 & 0.63 \\
\hline
\end{tabular}

230 MLR: the multivariate linear regression model; EOF: the empirical orthogonal function 231 model; PPEOF: the EOF model with mode1 replacing by phytoplankton primary 232 production $\left(P P_{\text {eu }}\right)$; QPR: the quadratic polynomial regression model; SQPR: the stepwise 233 QPR model; mSQPR: the modified SQPR model with all coefficients significant. $R^{2}$ : the 
234 coefficient of determination; RMSE: root mean square error; UPD: unbiased percent 235 difference; $M R D$ : and mean relative difference; $M B$ : mean bias; $M R$ : mean ratio. 
Table S4. Estimates of parameters and statistical information of proposed models.

\begin{tabular}{|c|c|c|c|c|c|c|c|}
\hline \multirow{2}{*}{ Model } & \multirow{2}{*}{$R^{2}$} & \multirow{2}{*}{ AIC } & \multicolumn{5}{|l|}{ Parameters } \\
\hline & & & Term & Coefficient & t-value & $p$-value & VIF \\
\hline \multirow{5}{*}{ MLR } & \multirow{5}{*}{0.79} & \multirow{5}{*}{43.26} & (Intercept) & 3.4281 & 74.25 & $<0.01$ & \\
\hline & & & Chla & 0.0242 & 3.92 & $<0.01$ & 1.45 \\
\hline & & & $\ln (\mathrm{LST})$ & -1.0095 & -8.17 & $<0.01$ & 3.07 \\
\hline & & & $\ln \left(K_{d}(P A R)\right)$ & 0.5103 & 4.76 & $<0.01$ & 1.78 \\
\hline & & & PAR & 0.0344 & 4.78 & $<0.01$ & 2.54 \\
\hline \multirow{5}{*}{ EOF } & \multirow{5}{*}{0.78} & \multirow{5}{*}{43.26} & (Intercept) & 3.4282 & 74.25 & $<0.01$ & \\
\hline & & & EOF1 & -0.3138 & -9.95 & $<0.01$ & 1.00 \\
\hline & & & EOF2 & 0.1920 & 4.64 & $<0.01$ & 1.00 \\
\hline & & & EOF3 & 0.5000 & 7.05 & $<0.01$ & 1.00 \\
\hline & & & EOF4 & -0.5565 & -5.28 & $<0.01$ & 1.00 \\
\hline \multirow{5}{*}{ PPEOF } & \multirow{5}{*}{0.79} & \multirow{5}{*}{45.25} & (Intercept) & 7.2337 & 18.26 & $<0.01$ & \\
\hline & & & PPeu & -0.5497 & -9.67 & $<0.01$ & 1.26 \\
\hline & & & EOF2 & 0.3895 & 8.31 & $<0.01$ & 1.23 \\
\hline & & & EOF3 & 0.4359 & 6.01 & $<0.01$ & 1.01 \\
\hline & & & EOF4 & -0.4164 & -3.84 & $<0.01$ & 1.02 \\
\hline \multirow{6}{*}{ QPR } & \multirow{6}{*}{0.82} & \multirow{6}{*}{42.26} & (Intercept) & 3.2408 & 28.60 & $<0.01$ & \\
\hline & & & Chla & 0.0238 & 2.53 & 0.02 & 3.94 \\
\hline & & & $\ln (\mathrm{LST})$ & -1.1463 & -4.35 & $<0.01$ & 16.45 \\
\hline & & & $\ln (\mathrm{KdPAR})$ & 0.5842 & 2.94 & 0.01 & 7.19 \\
\hline & & & PAR & 0.0439 & 2.65 & 0.01 & 15.83 \\
\hline & & & Chla $^{2}$ & 0.0012 & 1.37 & 0.18 & 2.97 \\
\hline
\end{tabular}




\begin{tabular}{|c|c|c|c|c|c|c|c|}
\hline & & & $\ln (\text { LST })^{2}$ & 0.1938 & 0.44 & 0.66 & 29.32 \\
\hline & & & $\ln \left(K_{d}(P A R)\right)^{2}$ & 0.2315 & 1.42 & 0.16 & 6.28 \\
\hline & & & PAR $^{2}$ & 0.0011 & 0.48 & 0.64 & 36.18 \\
\hline & & & Chla*In(LST) & -0.0043 & -0.19 & 0.85 & 7.46 \\
\hline & & & Chla*In(Kd(PAR $))$ & 0.0077 & 0.36 & 0.72 & 7.61 \\
\hline & & & Chla*PAR & 0.0008 & 0.59 & 0.56 & 8.40 \\
\hline & & & $\ln (\mathrm{LST})^{\star} \ln \left(K_{\mathrm{d}}(\mathrm{PAR})\right)$ & -0.1079 & -0.15 & 0.88 & 30.28 \\
\hline & & & $\ln (\mathrm{LST})^{\star} \mathrm{PAR}$ & -0.0334 & -0.58 & 0.56 & 103.33 \\
\hline & & & $\ln \left(K_{d}(\mathrm{PAR})\right)^{\star} \mathrm{PAR}$ & 0.0068 & 0.16 & 0.87 & 29.34 \\
\hline & & & (Intercept) & 3.2591 & 55.41 & $<0.01$ & \\
\hline & & & Chla & 0.0258 & 4.61 & $<0.01$ & 1.58 \\
\hline & & & $\ln (\mathrm{LST})$ & -0.9844 & -7.74 & $<0.01$ & 4.33 \\
\hline סחסר & & 10 & $\ln \left(K_{d}(P A R)\right)$ & 0.6732 & 5.35 & $<0.01$ & 3.27 \\
\hline 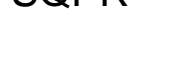 & & (60.7) & PAR & 0.0373 & 5.36 & $<0.01$ & 3.17 \\
\hline & & & Chla $^{2}$ & 0.0012 & 2.42 & $<0.01$ & 1.15 \\
\hline & & & $\ln \left(K_{\mathrm{d}}(\mathrm{PAR})\right)^{2}$ & 0.2049 & 2.35 & $<0.01$ & 2.01 \\
\hline & & & Chla*PAR & 0.0007 & 1.41 & 0.17 & 1.28 \\
\hline & & & (Intercept) & 3.2613 & 54.89 & $<0.01$ & \\
\hline & & & Chla & 0.0270 & 4.85 & $<0.01$ & 1.54 \\
\hline & & & $\ln (\mathrm{LST})$ & -0.9186 & -7.69 & $<0.01$ & 3.75 \\
\hline mSQPR & 0.84 & 30.73 & $\ln \left(K_{d}(P A R)\right)$ & 0.7253 & 5.96 & $<0.01$ & 2.99 \\
\hline & & & PAR & 0.0335 & 5.17 & $<0.01$ & 2.69 \\
\hline & & & Chla $^{2}$ & 0.0011 & 2.12 & 0.04 & 1.09 \\
\hline & & & $\ln \left(K_{d}(P A R)\right)^{2}$ & 0.2431 & 2.91 & $<0.01$ & 1.82 \\
\hline
\end{tabular}


237 Chla: chlorophyll-a; LST: lake surface temperature; $K_{d}(P A R)$ : diffuse attenuation 238 coefficient of photosynthetically active radiation; PAR: photosynthetically active radiation; 239 PP eu: phytoplankton primary production; EOF1-4: 4 orthogonal modes after empirical 240 orthogonal transforming of Chla, LST, $K_{d}(P A R)$ and PAR. MLR: the multivariate linear 241 regression model; EOF: the empirical orthogonal function model; PPEOF: the EOF model 242 with mode1 replacing by $P P_{\text {eu; }}$ QPR: the quadratic polynomial regression model; SQPR: 243 the stepwise QPR model; mSQPR: the modified SQPR model with all coefficients 244 significant. $R^{2}$ : the coefficient of determination; AIC: Akaike information criterion; VIF: 245 Variance Inflation Factors. 
Table S5. Model sensitivity to uncertainties in input variables.

\begin{tabular}{lllllll}
\hline $\begin{array}{l}\text { Variables } \\
\text { with uncertainty }\end{array}$ & Relative bias & $R M S E$ & UPD & $M R D$ & $M B$ & \\
& $\%$ & $\mu m o l L^{-1}$ & $\%$ & $\%$ & $\mu m o l L^{-1}$ & $M R$ \\
\hline Chla & $-31.57-78.16$ & 7.76 & $\mathbf{1 9 . 0 8}$ & 15.70 & 4.82 & 1.16 \\
LST & $-30.59-31.58$ & 3.75 & $\mathbf{8 . 1 7}$ & 2.34 & 1.18 & 1.02 \\
$K_{d}($ PAR $)$ & $-29.97-35.37$ & 4.30 & $\mathbf{8 . 9 6}$ & 3.70 & 1.36 & 1.04 \\
PAR & $-30.49-30.31$ & 4.08 & $\mathbf{1 0 . 1 8}$ & 5.38 & 1.94 & 1.05 \\
Chla, LST & $-29.16-80.44$ & 8.39 & $\mathbf{2 0 . 7 0}$ & 18.55 & 5.67 & 1.19 \\
Chla, Kd(PAR) & $-28.16-82.02$ & 8.65 & $\mathbf{2 1 . 3 5}$ & 19.38 & 5.41 & 1.19 \\
Chla, PAR & $-28.86-79.62$ & 8.62 & $\mathbf{2 2 . 2 2}$ & 20.41 & 5.89 & 1.20 \\
LST, Kd(PAR) & $-27.47-39.97$ & 5.03 & $\mathbf{1 0 . 9 8}$ & 7.02 & 2.33 & 1.07 \\
LST, PAR & $-27.93-38.35$ & 5.01 & $\mathbf{1 2 . 4 7}$ & 8.93 & 3.06 & 1.09 \\
$K_{d}($ PAR), PAR & $-27.09-38.35$ & 5.51 & $\mathbf{1 3 . 2 4}$ & 9.42 & 2.64 & 1.09 \\
Chla, LST, Kd(PAR) & $-25.57-85.35$ & 9.37 & $\mathbf{2 3 . 1 8}$ & 22.52 & 6.18 & 1.23 \\
Chla, LST, PAR & $-26.35-82.90$ & 9.34 & $\mathbf{2 3 . 9 7}$ & 23.55 & 6.74 & 1.24 \\
Chla, Kd(PAR), PAR & $-25.30-83.64$ & 9.51 & $\mathbf{2 4 . 3 8}$ & 23.97 & 6.13 & 1.24 \\
LST, Kd(PAR), PAR & $-24.44-43.26$ & 6.32 & $\mathbf{1 5 . 4 0}$ & 12.68 & 3.48 & 1.13 \\
Chla, LST, Kd(PAR), PAR & $-22.59-87.85$ & 10.24 & $\mathbf{2 6 . 1 4}$ & 27.19 & 6.97 & 1.27 \\
\hline Based & & & & & & \\
\hline
\end{tabular}

Based on previous studies, a conservative larger uncertainties of $30 \%, 15 \%, 35 \%$, and 248 20\% were defined in the MODIS-derived Chla (chlorophyll-a), LST (lake surface 249 temperature), $K_{d}(P A R)$ (diffuse attenuation coefficient of photosynthetically active 250 radiation), and PAR (photosynthetically active radiation), respectively. RMSE: root mean 251 square error; UPD: unbiased percent difference; $M R D$ : and mean relative difference; $M B$ : 252 mean bias; MR: mean ratio. 
253 Table S6. Model deviations caused by different random deviations of input variables.

\begin{tabular}{lllllll}
\hline $\begin{array}{l}\text { Variables } \\
\text { with }\end{array}$ & Relative bias & $R M S E$ & UPD & $M R D$ & $M B$ & \\
uncertainty & $\%$ & $\mu m o l L^{-1}$ & $\%$ & $\%$ & $\mu \mathrm{mol} \mathrm{L}^{-1}$ & \\
\hline Chla,10\% & $-33.14-43.53$ & 3.87 & 8.29 & 1.54 & 1.04 & 1.02 \\
Chla,20\% & $-32.56-56.56$ & 5.90 & 12.96 & 8.01 & 3.06 & 1.08 \\
LST,10\% & $-32.38-28.86$ & 3.47 & 7.74 & 0.27 & 0.45 & 1.00 \\
LST,20\% & $-28.48-35.82$ & 4.34 & 9.68 & 5.53 & 2.16 & 1.06 \\
Kd(PAR),10\% & $-33.19-27.42$ & 3.40 & 7.67 & -0.84 & 0.05 & 0.99 \\
Kd(PAR),20\% & $-32.75-28.90$ & 3.46 & 7.69 & 0.00 & 0.36 & 1.00 \\
Kd(PAR),30\% & $-31.25-32.79$ & 3.87 & 8.21 & 2.10 & 0.95 & 1.02 \\
PAR,10\% & $-32.67-27.80$ & 3.37 & 7.77 & 0.41 & 0.43 & 1.00 \\
PAR,30\% & $-27.11-47.09$ & 5.75 & 15.38 & 12.45 & 3.60 & 1.12 \\
\hline
\end{tabular}

254 Chla: chlorophyll-a; LST: lake surface temperature; $K_{d}(\mathrm{PAR})$ : diffuse attenuation 255 coefficient of photosynthetically active radiation; PAR: photosynthetically active radiation. 256 RMSE: root mean square error; UPD: unbiased percent difference; MRD: and mean 257 relative difference; $M B$ : mean bias; $M R$ : mean ratio. 


\section{References}

259

260

261

262

263

264

265

266

267

268

269

270

271

272

273

274

275

276

277

278

279

280

281

282

283

1. Xiao, Q.; Xu, X.; Duan, H.; Qi, T.; Qin, B.; Lee, X.; Hu, Z.; Wang, W.; Xiao, W.; Zhang,

M., Eutrophic Lake Taihu as a significant $\mathrm{CO}_{2}$ source during 2000-2015. Water Research 2020, 170, 115331.

2. Xue, K.; Ma, R.; Duan, H.; Shen, M.; Boss, E.; Cao, Z., Inversion of inherent optical properties in optically complex waters using sentinel-3A/OLCl images: A case study using China's three largest freshwater lakes. Remote Sensing of Environment 2019, 225, 328346.

3. Hu, C.; Chen, Z.; Clayton, T. D.; Swarzenski, P.; Brock, J. C.; Muller-Karger, F. E., Assessment of estuarine water-quality indicators using MODIS medium-resolution bands: Initial results from Tampa Bay, FL. Remote Sensing of Environment 2004, 93, (3), 423441.

4. Shen, M.; Duan, H.; Cao, Z.; Xue, K.; Loiselle, S.; Yesou, H., Determination of the Downwelling Diffuse Attenuation Coefficient of Lake Water with the Sentinel-3A OLCI. Remote Sensing 2017, 9, (12), 1246.

5. Hu, C. M.; Lee, Z. P.; Ma, R. H.; Yu, K.; Li, D. Q.; Shang, S. L., Moderate Resolution Imaging Spectroradiometer (MODIS) observations of cyanobacteria blooms in Taihu Lake, China. Journal of Geophysical Research-Oceans 2010, 115, 20.

6. Shi, K.; Zhang, Y.; Xu, H.; Zhu, G.; Qin, B.; Huang, C.; Liu, X.; Zhou, Y.; Lv, H., Longterm satellite observations of microcystin concentrations in lake taihu during cyanobacterial bloom periods. Environmentalence \& Technology 2015, 10, (6), 6448-56.

7. Liu, G.; Ou, W.; Zhang, Y.; Wu, T.; Zhu, G.; Shi, K.; Qin, B., Validating and mapping surface water temperatures in lake taihu: Results from modis land surface temperature products. IEEE Journal of Selected Topics in Applied Earth Observations \& Remote Sensing 2017, 8, (3), 1230-1244.

8. Huang, C. C.; Yao, L.; Huang, T.; Zhang, M. L.; Zhu, A. X.; Yang, H., Wind and rainfall 
regulation of the diffuse attenuation coefficient in large, shallow lakes from long-term MODIS observations using a semianalytical model. Journal of Geophysical Research: Atmospheres 2017, 122, (13), 6748-6763.

9. Frouin, R.; McPherson, J.; Ueyoshi, K.; Franz, B. A., A time series of photosynthetically available radiation at the ocean surface from SeaWiFS and MODIS data. SPIE: 2012; Vol. 8525.

10. Deng, Y.; Zhang, Y.; Li, D.; Shi, K.; Zhang, Y., Temporal and spatial dynamics of phytoplankton primary production in lake taihu derived from MODIS data. Remote Sensing 2017, 9, (3), 195.

11. Bailey, S. W.; Werdell, P. J., A multi-sensor approach for the on-orbit validation of ocean color satellite data products. Remote Sensing of Environment 2006, 102, (1), 1223.

12. Chen, S.; Hu, C.; Byrne, R. H.; Robbins, L. L.; Yang, B., Remote estimation of surface $\mathrm{pCO}_{2}$ on the West Florida Shelf. Continental Shelf Research 2016, 128, (Supplement C), 10-25.

13. Valerio, A. d. M.; Kampel, M.; Vantrepotte, V.; Ward, N. D.; Sawakuchi, H. O.; Less, D. F. D. S.; Neu, V.; Cunha, A.; Richey, J., Using CDOM optical properties for estimating DOC concentrations and $\mathrm{pCO}_{2}$ in the Lower Amazon River. Optics Express 2018, 26, (14), A657-A677.

14. Hu, Z.; Xiao, Q.; Yang, J.; Xiao, W.; Wang, W.; Liu, S.; Lee, X., Temporal Dynamics and Drivers of Ecosystem Metabolism in a Large Subtropical Shallow Lake (Lake Taihu). International Journal of Environmental Research and Public Health 2015, 12, (4).

15. Zhou, Y.; Jeppesen, E.; Zhang, Y.; Niu, C.; Shi, K.; Liu, X.; Zhu, G.; Qin, B., Chromophoric dissolved organic matter of black waters in a highly eutrophic Chinese lake: Freshly produced from algal scums? Journal of Hazardous Materials 2015, 299, 222-230. 16. Weyhenmeyer, G. A.; Kosten, S.; Wallin, M. B.; Tranvik, L. J.; Jeppesen, E.; Roland, F., Significant fraction of $\mathrm{CO}_{2}$ emissions from boreal lakes derived from hydrologic 
311 inorganic carbon inputs. Nature Geoscience 2015, 8, (12), 933-936.

312 17. Barnes, B. B.; Hu, C., Cross-Sensor Continuity of Satellite-Derived Water Clarity in

313 the Gulf of Mexico: Insights Into Temporal Aliasing and Implications for Long-Term Water

314 Clarity Assessment. IEEE Transactions on Geoscience and Remote Sensing 2015, 53, 315 (4), 1761-1772.

316 18. Cole, J. J.; Caraco, N. F., Atmospheric exchange of carbon dioxide in a low-wind

317 oligotrophic lake measured by the addition of SF6. Limnology and Oceanography 1998, 318 43, (4), 647-656. 